\title{
Cyclic Phosphatidic Acid Influences the Expression and Regulation of Cyclic Nucleotide Phosphodiesterase 3B and Lipolysis in 3T3-L1 cells
}

\author{
Tamotsu Tsukahara ${ }^{1 \#}$, Shuwa Hanazawa ${ }^{2}$ and Kimiko Murakami-Murofushi ${ }^{2}$ \\ ${ }^{1}$ Department of Integrative Physiology \& Bio-System Control, Shinshu University School of \\ Medicine, 3-1-1 Asahi, Matsumoto, Nagano 390-8621, Japan \\ ${ }^{2}$ Department of Biology ${ }^{2}$, Faculty of Science, Ochanomizu University, 2-1-1 Ohtsuka, \\ Bunkyo-ku 112-8610, Tokyo, Japan \\ ${ }^{\#}$ Corresponding Author: Tamotsu Tsukahara, Ph.D., Department of Integrative Physiology \& \\ Bio-System Control, Shinshu University School of Medicine, 3-1-1 Asahi, Matsumoto, \\ Nagano 390-8621, Japan, Tel\&Fax.: +81-263-37-2600, E-mail: ttamotsu @ shinshu-u.ac.jp \\ Abbreviations: TG, triglycerides; IBMX, 3-isobutyl-1-methylxanthine; PDE, \\ phosphodiesterase; FFA; free fatty acid; cAMP, cyclic adenosine monophosphate, TLC; thin \\ layer chromatography
}




\begin{abstract}
Cyclic phosphatidic acid (cPA) is found in cells from slime mold to humans and has a largely unknown function. We previously reported that cPA significantly inhibited the lipid accumulation in 3T3-L1 adipocytes through inhibition of PPAR $\gamma$ activation. We find here that cPA reduced intracellular triglyceride levels and inhibited the phosphodiesterase $3 \mathrm{~B}$ (PDE3B) expression in 3T3-L1 adipocytes. PPAR $\gamma$ activation in adipogenesis that can be blocked by treatment with cPA then participates in adipocyte function through inhibition of PDE3B expression. We also found the intracellular cAMP levels in 3T3-L1 adipocytes increased after exposure to $\mathrm{cPA}$. These findings contribute to the participation of $\mathrm{cPA}$ on the lipolytic activity in 3T3-L1 adipocytes. Our studies imply that cPA might be a therapeutic compound in the treatment of obesity and obesity-related diseases.
\end{abstract}




\section{Keyword}

Lysophospholipids, Cyclic phosphatidic acid, PPAR $\gamma$, Adipogenesis, Phosphodiesterase, Lipolysis

\section{Introduction}

Overweight and obesity are worldwide health problems. There are more than 1 billion overweight adults in the world, and there are at least 300 million clinically obese people [1]. Obesity is a condition in which adipocytes accumulate a large amount of body fat and become enlarged. Adipocytes play a critical role in lipid homeostasis and energy balance. Adipose differentiation is a complex process by which fibroblast-like undifferentiated cells are converted into cells that accumulate lipid droplets [2]. It has been reported that PPAR $\gamma$ plays a critical role in adipogenesis [2] [3]. PPAR $\gamma$ is a nuclear hormone receptor that plays an essential role in lipid and glucose homeostasis and predominantly expressed in the adipose tissue [2]. Upon agonist binding, PPAR $\gamma$ drives the expression of several adipocyte-specific genes [3] such as FABP4 (fatty acid binding protein 4) and CD36 (scavenger receptor). PPAR $\gamma$ agonists are known to induce the differentiation of preadipocytes into mature adipocyte. Physiological agonists include $15 \mathrm{~d}_{-} \mathrm{PGJ}_{2}$ [4], lysophospholipids, such as lysophosphatidic acid (LPA) [5] and alkyl glycerophosphate (AGP) [6], oxidized phospholipids [7] and nitrated fatty acids [8]. The thiazolidinediones agonists, including rosiglitazone and pioglitazone are widely used in type II diabetes mellitus to improve insulin sensitivity by inducing the expression of genes involved in adipocyte differentiation, lipid and glucose uptake, and fatty acid storage [9] [10] [11]. Furthermore, PPAR $\gamma$ activation is also known to be necessary and sufficient for neointimal lesion formation [12]. Neointima formation is an early step in the development of atherosclerotic plaques [13] [14]. Atherogenic lesions progress through a prolonged process of lipid accumulation and can trigger ischemic attack or stroke [15]. Recent studies indicate that PPAR $\gamma$ antagonists are able to inhibit adipocyte differentiation. The bisphenol A diglycidyl ether (BADGE) has been shown to possess both agonist and antagonist activities toward PPAR $\gamma$, and to block the 
ability of adipogenic cell lines such as 3T3-L1 and 3T3-F442A cells [16]. T0070907 was identified as a potent and selective PPAR $\gamma$ antagonist and it also inhibited lipid accumulation in 3T3-L1 cells [17]. We have been reported that $\mathrm{cPA}$ is a specific and high-affinity antagonist of PPAR $\gamma$ [18] [19] [20]. cPA is a naturally occurring analog of LPA in which the $s n-2$ hydroxy group forms a 5-membered ring with the $s n-3$ phosphate [21] [22,23]. cPA is generated by transphosphatidylation of lysophosphatidyl choline (LPC) catalyzed by phospholipase D [24].

In 3T3-L1 adipocytes, investigations on PDE have focused on hormone-sensitive PDE3B activity and its expression [25] [26]. PDE3B is found in adipocytes and pancreatic $\beta$-cells [25] [27], and levels of PDE3B mRNA and protein are lower in white adipose tissue of rodents model [28]. Furthermore, decreases in PDE3B activity is accompanied by increases in intracellular cAMP that in turn lead to the activation of cAMP-dependent protein kinase A (PKA). This then leads to the activation of hormone-sensitive lipase (HSL), subsequently to an increase in the stored TG hydrolysis rate, and finally to increases in the release of FFA and glycerol from adipocytes. In this article, we report show that the PPAR $\gamma$ antagonist cPA inhibits differentiation of adipocyte, downregulation of PDE3B expression, increase of intracellular cAMP production, and stimulated lipolysis activity in 3T3-L1 adipocytes.

\section{Materials and methods}

\subsection{Reagents and Antibodies}

Cyclic phosphatidic acid (16:0) was purchased from Avanti Polar Lipids (Alabaster, AL, USA). Carba cyclic phosphatidic acids, 3ccPA and 2ccPA, were chemically synthesized according to Uchiyama et al [29]. Purity of cPA or ccPA were confirmed by TLC and negative ion liquid chromatography-mass spectrometry (data not shown). Rosiglitazone was purchased from ALEXIS Biochemicals (Lausen, Switzerland) and prepared as a $10 \mathrm{mM}$ stock in ethanol. T0070907 was purchased from Cayman chemical company (Ann Arbor, Michigan, USA). GW9662, 3-isobutyl-1-methylxanthine (IBMX), dexamethasone, cilostazol and insulin (from bovine pancreas) were purchased from Sigma Aldrich (St Louis, MO, USA). PDE inhibitors (for PDE1, PDE2 and PDE4), anti-PPAR $\gamma$ antibody (sc-7196), anti PDE3B antibody (sc-20793) and anti $\beta$-actin antibody (sc-47778) were purchased from Santa Cruz Biotechnology (Santa Cruz, CA, USA).

\subsection{Cell culture}

Murine 3T3-L1 cells were purchased from American Type Culture Collection (VA, USA) 
and cultured in Dulbecco's modified Eagle's medium supplemented with fetal calf serum and antibiotics. Adipocyte differentiation of 3T3-L1 cells was induced by incubation of the cells for 2 days in differentiation medium supplement with insulin $(10 \mu \mathrm{g} / \mathrm{ml}), 1 \mu \mathrm{M}$ dexamethasone, and $500 \mu \mathrm{M}$ IBMX. On day 2, the medium was replaced with growth medium containing insulin $(10 \mu \mathrm{g} / \mathrm{ml})$ alone and changed every 2 days. Adipocytes were used for experiments 7-10 days after initiating differentiation.

\subsection{Cell viability assay}

Trypan blue dye exclusion method is used to determine the number of viable cells present in a cell suspension using hemocytometer.

\subsection{Oil Red O staining}

The extent of differentiation was determined by the amount of lipid accumulation at 10 days by Lipid Staining Kit (Zen-Bio, Inc., NC, USA). Briefly, cells were fixed in fixative solution for $1 \mathrm{~h}$ and then stained with $0.6 \%$ oil red $\mathrm{O}$ solution in isopropyl alcohol/ $\mathrm{H}_{2} \mathrm{O}(60: 40, \mathrm{v} / \mathrm{v})$ for $1 \mathrm{~h}$ at room temperature, washed four times with distilled water, and dried. Differentiation was examined by visual inspection and quantified by elution with isopropyl alcohol and an optical density measurement at $590 \mathrm{~nm}$ (Beckman DU-640).

\subsection{Reporter gene assay}

To determine endogenous PPAR $\gamma$ activation, 3T3-L1 cells were co-transfected with pGL3bPPRE (ACO)-Fluc and pSV40- $\beta$-galactosidase plasmids and subjected to the reporter gene assay as described before. Twenty four hours after transfection, cells were treated with indicated compounds and cultured for an additional $20 \mathrm{~h}$. Luciferase activity was measured with the Steady-Glo luciferase Assay System (Promega, WI, USA) using the SpectraMax plate reader (Molecular Devices, CA, USA).

\subsection{Lipolysis Assay}

Lypolysis was measured as glycerol release an adipocyte suspension by Lipolysis Assay Kit (Zen-Bio, Inc. Research Triangle Park, NC, USA). 3T3-L1 cells are plated in 96 well plates and allowed to differentiate under the standard differentiation condition for 1 week. Confluent monolayers of adipocytes were washed with PBS and exposed to PDE inhibitors ( $5 \mu \mathrm{M}$ each) or cPA $(0.1-30 \mu \mathrm{M})$ or vehicle in phenol red-free DMEM with $2 \%$ fatty acid-free BSA for up to $18 \mathrm{~h}$ at $37^{\circ} \mathrm{C}$ in $5 \% \mathrm{CO}_{2}$ incubator. Cells were then washed with cold PBS and lysed in $1 \%$ 
Triton X-100 buffer, and the protein concentration was determined and used to normalize glycerol release. Culture supernatants were collected and analyzed for glycerol, a breakdown product of TG.

\subsection{Quantitative real-time PCR analysis}

Total RNA was prepared using TRIzol reagent (Invitrogen, CA, USA) from 3T3-L1 $\left(2 \times 10^{5}\right.$ cell). One $\mu \mathrm{g}$ of total RNA was used for the subsequent synthesis of cDNA using the FirstStrand Synthesis kit (Promega, Madison, WI, USA) as recommended by the manufacturer. Quantification of mRNA levels was measured by using a real-time PCR system (Applied Biosystems, CA, USA) and First Start Universal SYBR Green PCR Master (Roche Applied Science, Germany) with the following primer pair sets: PDE3B, 5'-

CCAGGTGTGCATCAAATTAGCA-3' (F) and 5'-CAATGCCTTCTGTCCATCTCAA3'(R); CD36, 5'-GCCTCCTTTCCACCTTTTGT-3' (F) and 5'-

TCTGTACACGGGGATTCCTT-3' (R); FABP4, 5'-

CTTCGATGATTACATGAAAGAAGTG-3' (F) and 5'-ACGCCCAGTTTGAAGGAAAT3' (R); GAPDH, 5'-CTGCACCACCAACTGCTTAG (F) and 5'GGGCCATCCACAGTCTTCT-3' (R)

\subsection{Western blot analysis}

Cells were washed twice with ice-cold PBS and solubilized with whole-cell extraction buffer (20 mM HEPES (pH 7.9), 0.5\% NP-40, 15\% glycerol, 300 mM NaCl, 1 mM EDTA, 10 mM $\mathrm{NaF}, 1 \mathrm{mM} \mathrm{Na} \mathrm{VO}_{4}, 1 \mathrm{mM}$ DTT, $1 \mu \mathrm{g} / \mathrm{ml}$ leupeptin, $1 \mu \mathrm{g} / \mathrm{ml}$ pepstatin, $1 \mu \mathrm{g} / \mathrm{ml}$ aprotinin and $0.5 \mathrm{mM}$ PMSF). The cell lysate was centrifuged at $14,000 \times \mathrm{g}$ for $5 \mathrm{~min}$, and the protein in the supernatant was quantified using Bradford protein assay reagent (Bio-Rad, CA, USA). Total protein was diluted 1:4 with lane marker reducing sample buffer (ThermoFisher Scientific, MA, USA) and boiled for 5 min. The resultant protein was then separated on $10 \%$ SDSPAGE and transferred onto a PVDF membrane (GE Healthcare, NJ, USA). The membrane was blocked by $5 \%$ skim milk in TBS (Tris-buffered saline) with $0.1 \%$ Tween 20 (pH 7.6) for $1 \mathrm{~h}$ at room temperature and probed with primary rabbit anti-human PDE3B and actin antibody (Santa Cruz Biotechnology, Santa Cruz, CA, USA) at $4^{\circ} \mathrm{C}$ overnight. After washing, the membrane was incubated with secondary anti-rabbit antibody for $1 \mathrm{~h}$ at room temperature and then developed with ECL-plus chemiluminescent detection reagent (GE Healthcare, Piscataway, NJ, USA). 


\subsection{Effect of cPA on intracellular cAMP level}

The differentiated 3T3-L1 cells were incubated in medium containing cPA for $6 \mathrm{~h}$. cAMP levels in cell extracts were measured by ELISA (cAMP Biotrak Enzyme immunoassay system, Amersham Biosciences) in 96-well plates on a spectrophotometer at $450 \mathrm{~nm}$ according to the manufacturer's instructions.

\section{Results and discussion}

\section{1 cPA is an adipogenic antagonist through PPAR inhibition}

As mentioned above, we have described that cPA (Fig. 1A, upper) inhibited the lipid accumulation in 3T3-L1 adipocytes. To confirm our previous observations, we designed and performed more detailed studies. As shown in Fig. 1B, a viability assay was used to determine any possible adverse effects of cPA. The viability of cultured 3T3-L1 cells was not affected by incubation in differentiation buffer with various concentration of cPA (up to 10 $\mu M)$. PPAR $\gamma$ is a master regulator in the formation of fat cell, and two PPAR $\gamma$ isoforms $\left(\operatorname{PPAR} \gamma_{1}\right.$ and PPAR $\gamma_{2}$ ) have been found in adipocytes [2]. We examined the expression level of PPAR $\gamma$ in 3T3-L1 cells using Western blot analysis. The expression of PPAR $\gamma_{2}$ protein in 3T3-L1 cells increased accompanying by the differentiation to adipocyte after addition of differentiation buffer (Fig. 1C). We then investigated whether cPA could block the induction of adipogenesis in 3T3-L1 cells. As shown in Fig.1D and E, the standard differentiation treatment with dexamethasone, IBMX, and insulin promoted lipid accumulation in 3T3-L1 cells. In contrast, lipid accumulation in these cells was obviously inhibited when cells were treated with both $\mathrm{cPA}$ and the differentiation mixture. These results suggest that significant reduction in lipid accumulation is not due to toxic side effect by cPA. The synthetic PPAR $\gamma$ antagonists, such as T0070907 and GW9662 have also exhibited strong inhibitory effects of adipogenesis. To confirm the PPAR $\gamma$ receptor in 3T3-L1 cells is functional, we transfected the cells with a luciferase reporter plasmid. Following treatment of cell lines with differentiation buffer, cPA and T0070907 inhibited the PPAR $\gamma$ activation elicited by rosiglitazone (Fig. 2A). These data suggest that $\mathrm{cPA}$ inhibits the PPAR $\gamma$-dependent transcriptional responses in 3T3-L1 adipocytes. PPAR $\gamma$ agonists are known to promote the conversion of a variety of preadipocyte into mature adipocyte [30]. Incubation of 3T3-L1 cells with $1 \mu \mathrm{M}$ rosiglitazone for 7 days resulted in their efficient conversion to adipocytes (Fig.2B), as indicated by the increase in Oil-red O staining (Fig.2C) and the induction of adipocyte specific gene, FABP4 and CD36 (Fig.2D). In contrast, when the cells were co- 
treated with $10 \mu \mathrm{M}$ cPA, a significant conversion to the adipocyte phenotype was not observed. Thus, cPA is proposed to be a potent antagonist of adipocyte differentiation in 3T3L1 cells.

\subsection{Effect of cPA on PDE3B mRNA and protein expression in 3T3-L1 adipocytes}

As it remains a matter of debate how cPA mediates its function on the regulation of adipogenesis. We assess the ability of selective PDE inhibitors to induce lipolysis in 3T3-L1 adipocytes. PDE is a key enzyme involved in the anti-lipolytic action and PDE activation results in a reduced intracellular cAMP level [31]. It has been reported that the main type of PDE expressed in insulin-sensitive cells, such as adipocytes, is PDE3B [32]. As shown in Fig.2E, inhibition of PDE3 with specific inhibitor, cilostazol $(5 \mu \mathrm{M})$ activated glycerol release from 3T3-L1 adipocytes. In contrast, each inhibitors for PDE1 (8-MethoxymethylIBMX), PDE2 (EHNA) and PDE4 (Rolipram) (5 $\mu \mathrm{M}$ each) did not significantly stimulated lipolysis in 3T3-L1 adipocytes. These observations led us to assume that PDE3 inhibitors are capable of inducing degradation of TG to glycerol and FFA in 3T3-L1 adipocytes. It was reported that the down-regulation of PDE3B gene expression correlated with the decrease in PDE3B protein expression and activity in white adipose tissue of animal model for type II diabetes [28]. We then performed the effect of cPA on the expression level of PDE3B mRNA in 3T3-L1 adipocytes on the day 7 after induction. Interestingly, PPAR $\gamma$ agonist, rosiglitazone significantly up-regulated PDE3B gene expression and increased the expression level of PDE3B mRNA up to 3.5-fold compared with vehicle alone. In contrast, co-treatment of 3T3L1 adipocytes with cPA or T0070907 results in decreased PDE3B gene expression (Fig. 3A). PDE3B protein was then quantified by Western blotting using anti-PDE3B antibody (Fig.3B). In treated cells with rosiglitazone, expression of PDE3B protein was increased to 1.9-fold compared to vehicle alone. This rise of PDE3B protein level was also suppressed by treatment with cPA or T0070907. Based on these data, we proposed that PDE3B might act through a PPAR $\gamma$ dependent regulation.

\section{3 cPA stimulates intracellular cAMP production}

Mukai et al. reported that cPA elevates intracellular cAMP concentration in MM1 cell line [33] [34]. However, the mechanism by which PDE3B initiates activation of intracellular cAMP production by cPA is still unclear. To address this question, we examined the effects 
of cPA on the intracellular cAMP concentration in 3T3-L1 adipocytes. As shown in Fig.3C, treatment of adipocytes with cPA significantly increased the amount of free glycerol. This is suggests that TG was hydrolyzed in adipocytes to FFA and glycerol through the lypolisis. We next examined the level of intracellular cAMP in 3T3-L1 adipocytes, and the cAMP level in 3T3-L1 adipocytes by cPA or ccPA (1 and $10 \mu \mathrm{M})$ was observed (Fig.3D). From these results, cPA is shown to influence the degradation of TG converting into free glycerol by inhibiting PDE3B expression, and subsequent increase of intracellular cAMP level is caused (Fig.4). These results suggest that cPA effects are associated with a decrease in the PPAR $\gamma$ activation as well as a diminished expression of PDE3B. cAMP-regulated lipolytic reaction in adipocytes is the critical gateway for stored energy release in cells [31]. Our data show that, cPA stimulates lipolysis might, at least in part, be caused by cPA. Further experiments are required in order to dissect the cross talk between these molecules. However, these studies support the potential use of cPA and its derivative as a therapeutic compound for obesity and obesity-related diseases.

\section{Conclusion}

Our in vitro data demonstrate that cPA effectively inhibits adipogenesis and stimulates lipolysis-activity. Thus, it is reasonable to postulate that the suppression of PPAR $\gamma$ activity is one of the mechanisms of metabolic disorders protection of cPA. Furthermore, cPA-inhibited PDE3B expression may serve as an important rescue mechanism of obesity. Our observation suggests that inhibition of PDE3B expression is required for efficient stimulation of lipolysis in murine adiopcytes. The impact of these effects on the efficacy of $\mathrm{cPA} / \mathrm{ccPA}$ treatment warrants further investigation for human model.

\section{Acknowledgement}

This work was supported in part by Grants-in-Aid for Scientific Research (C) 22591482 (to T.T.) from Japan Society for the Promotion of Science (JSPS) and the American Heart Association Grants 0525489B (to T.T.).

\section{References}

[1] WHO, Global strategy on diet, physical activity and health, (2009).

[2] P. Tontonoz, E. Hu, B.M. Spiegelman, Stimulation of adipogenesis in fibroblasts by PPAR gamma 2, a lipid-activated transcription factor, Cell 79 (1994) 1147-1156.

[3] M. Evans, Y. Park, M. Pariza, L. Curtis, B. Kuebler, M. McIntosh, Trans-10,cis-12 conjugated linoleic acid reduces triglyceride content while differentially affecting peroxisome proliferator activated receptor gamma2 and aP2 expression in 3T3-L1

preadipocytes, Lipids 36 (2001) 1223-1232. 
[4] B.M. Forman, P. Tontonoz, J. Chen, R.P. Brun, B.M. Spiegelman, R.M. Evans, 15Deoxy-delta 12, 14-prostaglandin $\mathrm{J} 2$ is a ligand for the adipocyte determination factor PPAR gamma, Cell 83 (1995) 803-812.

[5] T.M. McIntyre, A.V. Pontsler, A.R. Silva, A. St Hilaire, Y. Xu, J.C. Hinshaw, G.A. Zimmerman, K. Hama, J. Aoki, H. Arai, G.D. Prestwich, Identification of an intracellular receptor for lysophosphatidic acid (LPA): LPA is a transcellular PPARgamma agonist, Proc Natl Acad Sci U S A 100 (2003) 131-136.

[6] T. Tsukahara, R. Tsukahara, S. Yasuda, N. Makarova, W.J. Valentine, P. Allison, H. Yuan, D.L. Baker, Z. Li, R. Bittman, A. Parrill, G. Tigyi, Different residues mediate recognition of 1-O-oleyllysophosphatidic acid and rosiglitazone in the ligand binding domain of peroxisome proliferator-activated receptor gamma, J Biol Chem 281 (2006) 3398-3407.

[7] S.S. Davies, A.V. Pontsler, G.K. Marathe, K.A. Harrison, R.C. Murphy, J.C. Hinshaw, G.D. Prestwich, A.S. Hilaire, S.M. Prescott, G.A. Zimmerman, T.M. McIntyre, Oxidized alkyl phospholipids are specific, high affinity peroxisome proliferatoractivated receptor gamma ligands and agonists, J Biol Chem 276 (2001) 1601516023.

[8] Y. Li, J. Zhang, F.J. Schopfer, D. Martynowski, M.T. Garcia-Barrio, A. Kovach, K. Suino-Powell, P.R. Baker, B.A. Freeman, Y.E. Chen, H.E. Xu, Molecular recognition of nitrated fatty acids by PPAR gamma, Nat Struct Mol Biol 15 (2008) 865-867.

[9] K.F. Petersen, M. Krssak, S. Inzucchi, G.W. Cline, S. Dufour, G.I. Shulman, Mechanism of troglitazone action in type 2 diabetes, Diabetes 49 (2000) 827-831.

[10] D.A. Greene, Rosiglitazone: a new therapy for Type 2 diabetes, Expert Opin Investig Drugs 8 (1999) 1709-1719.

[11] G. Boden, C. Homko, M. Mozzoli, L.C. Showe, C. Nichols, P. Cheung, Thiazolidinediones upregulate fatty acid uptake and oxidation in adipose tissue of diabetic patients, Diabetes 54 (2005) 880-885.

[12] C. Zhang, D.L. Baker, S. Yasuda, N. Makarova, L. Balazs, L.R. Johnson, G.K. Marathe, T.M. McIntyre, Y. Xu, G.D. Prestwich, H.S. Byun, R. Bittman, G. Tigyi, Lysophosphatidic acid induces neointima formation through PPARgamma activation, J Exp Med 199 (2004) 763-774.

[13] W. Siess, G. Tigyi, Thrombogenic and atherogenic activities of lysophosphatidic acid, J Cell Biochem 92 (2004) 1086-1094.

[14] Y. Cheng, N. Makarova, R. Tsukahara, H. Guo, E. Shuyu, P. Farrar, L. Balazs, C. Zhang, G. Tigyi, Lysophosphatidic acid-induced arterial wall remodeling: requirement of PPARgamma but not LPA1 or LPA2 GPCR, Cell Signal 21 (2009) 1874-1884.

[15] A.I. Qureshi, E. Feldmann, C.R. Gomez, S.C. Johnston, S.E. Kasner, D.C. Quick, P.A. Rasmussen, M.F. Suri, R.A. Taylor, O.O. Zaidat, Intracranial atherosclerotic disease: an update, Ann Neurol 66 (2009) 730-738.

[16] H.M. Wright, C.B. Clish, T. Mikami, S. Hauser, K. Yanagi, R. Hiramatsu, C.N. Serhan, B.M. Spiegelman, A synthetic antagonist for the peroxisome proliferator-activated receptor gamma inhibits adipocyte differentiation, J Biol Chem 275 (2000) 18731877.

[17] G. Lee, F. Elwood, J. McNally, J. Weiszmann, M. Lindstrom, K. Amaral, M. Nakamura, S. Miao, P. Cao, R.M. Learned, J.L. Chen, Y. Li, T0070907, a selective ligand for peroxisome proliferator-activated receptor gamma, functions as an antagonist of biochemical and cellular activities, J Biol Chem 277 (2002) 19649-19657.

[18] T. Tsukahara, R. Tsukahara, Y. Fujiwara, J. Yue, Y. Cheng, G. H., A.L. Bolen, C. Zhang, L. Balazs, F. Re, G. Du, M.A. Frohman, D.L. Baker, A. Parrill, A. Uchiyama, K. Tetsuyuki, K. Murofushi, G. Tigyi, Phospholipase D2-dependent Inhibition of the Nuclear Hormone Receptor PPAR y by Cyclic Phosphatidic Acid, Mol. Cell 39

(2010) 421-432. 
[19] T. Tsukahara, S. Hanazawa, T. Kobayashi, Y. Iwamoto, K. Murakami-Murofushi, Cyclic phosphatidic acid decreases proliferation and survival of colon cancer cells by inhibiting peroxisome proliferator-activated receptor gamma, Prostaglandins Other Lipid Mediat 93 (2010) 126-133.

[20] G. Tigyi, Aiming drug discovery at lysophosphatidic acid targets, Br J Pharmacol 161 (2010) 241-270.

[21] K. Murakami-Murofushi, M. Shioda, K. Kaji, S. Yoshida, H. Murofushi, Inhibition of eukaryotic DNA polymerase alpha with a novel lysophosphatidic acid (PHYLPA) isolated from myxoamoebae of Physarum polycephalum, J Biol Chem 267 (1992) 21512-21517.

[22] K. Murakami-Murofushi, A. Uchiyama, Y. Fujiwara, T. Kobayashi, S. Kobayashi, M. Mukai, H. Murofushi, G. Tigyi, Biological functions of a novel lipid mediator, cyclic phosphatidic acid, Biochim Biophys Acta 1582 (2002) 1-7.

[23] K. Murakami-Murofushi, M. Mukai, S. Kobayashi, T. Kobayashi, G. Tigyi, H. Murofushi, A novel lipid mediator, cyclic phosphatidic acid (cPA), and its biological functions, Ann N Y Acad Sci 905 (2000) 319-321.

[24] P. Friedman, R. Haimovitz, O. Markman, M.F. Roberts, M. Shinitzky, Conversion of lysophospholipids to cyclic lysophosphatidic acid by phospholipase D, J Biol Chem 271 (1996) 953-957.

[25] T. Rahn Landstrom, J. Mei, M. Karlsson, V. Manganiello, E. Degerman, Downregulation of cyclic-nucleotide phosphodiesterase 3B in 3T3-L1 adipocytes induced by tumour necrosis factor alpha and cAMP, Biochem J 346 Pt 2 (2000) 337-343.

[26] E. Degerman, T.R. Landstrom, J. Wijkander, L.S. Holst, F. Ahmad, P. Belfrage, V. Manganiello, Phosphorylation and activation of hormone-sensitive adipocyte phosphodiesterase type 3B, Methods 14 (1998) 43-53.

[27] L. Guo, Q. Li, W. Wang, P. Yu, H. Pan, P. Li, Y. Sun, J. Zhang, Apelin inhibits insulin secretion in pancreatic beta-cells by activation of PI3-kinase-phosphodiesterase 3B, Endocr Res 34 (2009) 142-154.

[28] T. Nagaoka, T. Shirakawa, T.W. Balon, J.C. Russell, Y. Fujita-Yamaguchi, Cyclic nucleotide phosphodiesterase 3 expression in vivo: evidence for tissue-specific expression of phosphodiesterase 3A or 3B mRNA and activity in the aorta and adipose tissue of atherosclerosis-prone insulin-resistant rats, Diabetes 47 (1998) $1135-1144$.

[29] A. Uchiyama, M. Mukai, Y. Fujiwara, S. Kobayashi, N. Kawai, H. Murofushi, M. Inoue, S. Enoki, Y. Tanaka, T. Niki, T. Kobayashi, G. Tigyi, K. Murakami-Murofushi, Inhibition of transcellular tumor cell migration and metastasis by novel carbaderivatives of cyclic phosphatidic acid, Biochim Biophys Acta 1771 (2007) 103-112.

[30] D.L. Gerhold, F. Liu, G. Jiang, Z. Li, J. Xu, M. Lu, J.R. Sachs, A. Bagchi, A. Fridman, D.J. Holder, T.W. Doebber, J. Berger, A. Elbrecht, D.E. Moller, B.B. Zhang, Gene expression profile of adipocyte differentiation and its regulation by peroxisome proliferator-activated receptor-gamma agonists, Endocrinology 143 (2002) 21062118.

[31] K. Omori, J. Kotera, Overview of PDEs and their regulation, Circ Res 100 (2007) 309327.

[32] E. Degerman, P. Belfrage, A.H. Newman, K.C. Rice, V.C. Manganiello, Purification of the putative hormone-sensitive cyclic AMP phosphodiesterase from rat adipose tissue using a derivative of cilostamide as a novel affinity ligand, J Biol Chem 262 (1987) 5797-5807.

[33] M. Mukai, F. Imamura, M. Ayaki, K. Shinkai, T. Iwasaki, K. Murakami-Murofushi, H. Murofushi, S. Kobayashi, T. Yamamoto, H. Nakamura, H. Akedo, Inhibition of tumor invasion and metastasis by a novel lysophosphatidic acid (cyclic LPA), Int J 
[34] M. Mukai, H. Nakamura, M. Tatsuta, T. Iwasaki, A. Togawa, F. Imamura, H. Akedo, Hepatoma cell migration through a mesothelial cell monolayer is inhibited by cyclic AMP-elevating agents via a Rho-dependent pathway, FEBS Lett 484 (2000) 69-73.

\section{Figure legend}

Fig.1. Effect of inhibition of PPAR $\gamma$ on differentiation of 3T3-L1 preadipocytes. A, Structural formulas of compounds examined in the present study. B, Cell viability of maturing preadipocytes incubated with different concentrations of cPA $(1,5$ and $10 \mu \mathrm{M})$ is shown relative to vehicle treated cells set as $100 \%$ (mean \pm SEM, $n=3$ ). C, Expression of PPAR $\gamma$ during differentiation of 3T3-L1 preadipocytes. Total protein was isolated from two-day postconfluent (day 0) preadipocytes and various time points after induction of differentiation by the addition of differentiation buffer (D.B.) D, Two-day postconfluent (day 0) 3T3-L1 preadipocytes were induced to differentiate by using the standard differentiation protocol. Representative micrographs of Oil Red O staining of 3T3-L1 cells differentiated in vitro for 10 days in the presence or absence of $10 \mu \mathrm{M} \mathrm{cPA}(16: 0)$ added either at the induction of differentiation. The synthetic PPAR $\gamma$ antagonist, $10 \mu \mathrm{M}$ T0070907 and GW9662 were used as positive control. Magnification $\times 200$. E, Oil Red O was eluted by 2-propanol and quantified at $490 \mathrm{~nm}$ (mean $\pm \mathrm{SEM} \mathrm{n}=3, * * p<0.01$ based on Student's $t$-test). D.B. Differentiation buffer.

Fig.2 A, Undifferentiated or differentiated 3T3-L1 cells were transfected with the PPRE-luc and CMV- $\beta$-galactosidase plasmids and treated with vehicle or the indicated PPAR $\gamma$ ligand for $20 \mathrm{~h}$. The level of luciferase activity was measured in lysates of treated cells and normalized to $\beta$-galactosidase activity (mean \pm SEM $n=4$, ** $p<0.01$ based on Student's $t$ test). B and C, effect of cPA on IBMX/dexamethasone/insulin-induced differentiation of 3T3$\mathrm{L} 1$ cells. Cells were pretreated with cPA or vehicle for $1 \mathrm{~h}$ and then induced with differentiation buffer with or without cPA for 6 days. Cells were stained with Oil Red O. D, real-time PCR analysis of 3T3-L1 cells for adipocyte specific genes after treatment of cells for 7 days (mean \pm SEM $n=3$, $* * p<0.01$ based on Student's $t$-test). E, Effect of selsective PDE inhibitors (8-Methoxymethyl-IBMX for PDE1 inhibitor, EHNA for PDE2 inhibitor, cilostazol for PDE3 inhibitor and Rolipram for PDE4 inhibitor) on lipolysis in 3T3-L1 adipocytes (mean \pm SEM $n=3, * * p<0.01$ based on Student's $t$-test). 
Fig.3 A, Real-time PCR measurement of PDE3B mRNA expression, PDE3B and GAPDH (as internal control) on day 0 (cells in DMEM) and day 9 (cells in differentiation buffer containing rosiglitazone with or without cPA or T0070907) in 3T3-L1 cells (mean \pm SEM $\mathrm{n}=3$, ** $p<0.01$ based on Student's $t$-test). B, Western blotting was carried out using the antiPDE3B antibody as described in Materials and methods. Quantitative analysis of PDE3B protein in 3T3-L1 adipocyte. The mean value of PDE3B protein intensity of the differentiated 3T3-L1 cells is defined as 1.0, and the fold induction is shown as mean $\pm \operatorname{SEM}(n=3$, $*^{* *} p<0.01$ based on Student's $t$-test). C, cPA stimulates lipolysis. 3T3-L1 adipocytes were treated with cPA. Glycerol release was measured in defferentiated cells after treatment with cPA for $6 \mathrm{~h}$ (mean \pm SEM $n=3,{ }^{*} p<0.01$ based on Student's $t$-test). Glycerol content is given in $\mu \mathrm{M}$. D, cAMP response in cPA-stimulated differentiated adipocytes. After 7 days of differentiation, cells were incubated with cPA16:0 or metabolically stabilized carba derivatives $3 \mathrm{ccPA}$ and 2ccPA. Intracellular cAMP levels were measured in cell lysates from cultures using cAMP Biotrak Enzyme immunoassay system (mean \pm SEM $n=4,{ }^{*} \mathrm{p}<0.05$, ${ }^{* *} p<0.01$ based on Student's $t$-test). Cilostazol $(1 \mu \mathrm{M})$ used as positive control.

Fig.4. Schematic representation of the proposed mechanisms of cPA action in 3T3-L1 adipocytes. cPA enters the cells and binds to the PPAR $\gamma$. cPA suppresses adipocyte differentiation by preventing binding of rosiglitazone, and by inhibiting PDE3B gene expression and subsequently increasing intracellular cAMP level. These combined effects may contribute to the inhibition of adipocyte differentiation, as well as the degradation of TG increased by lipolysis-activity. 

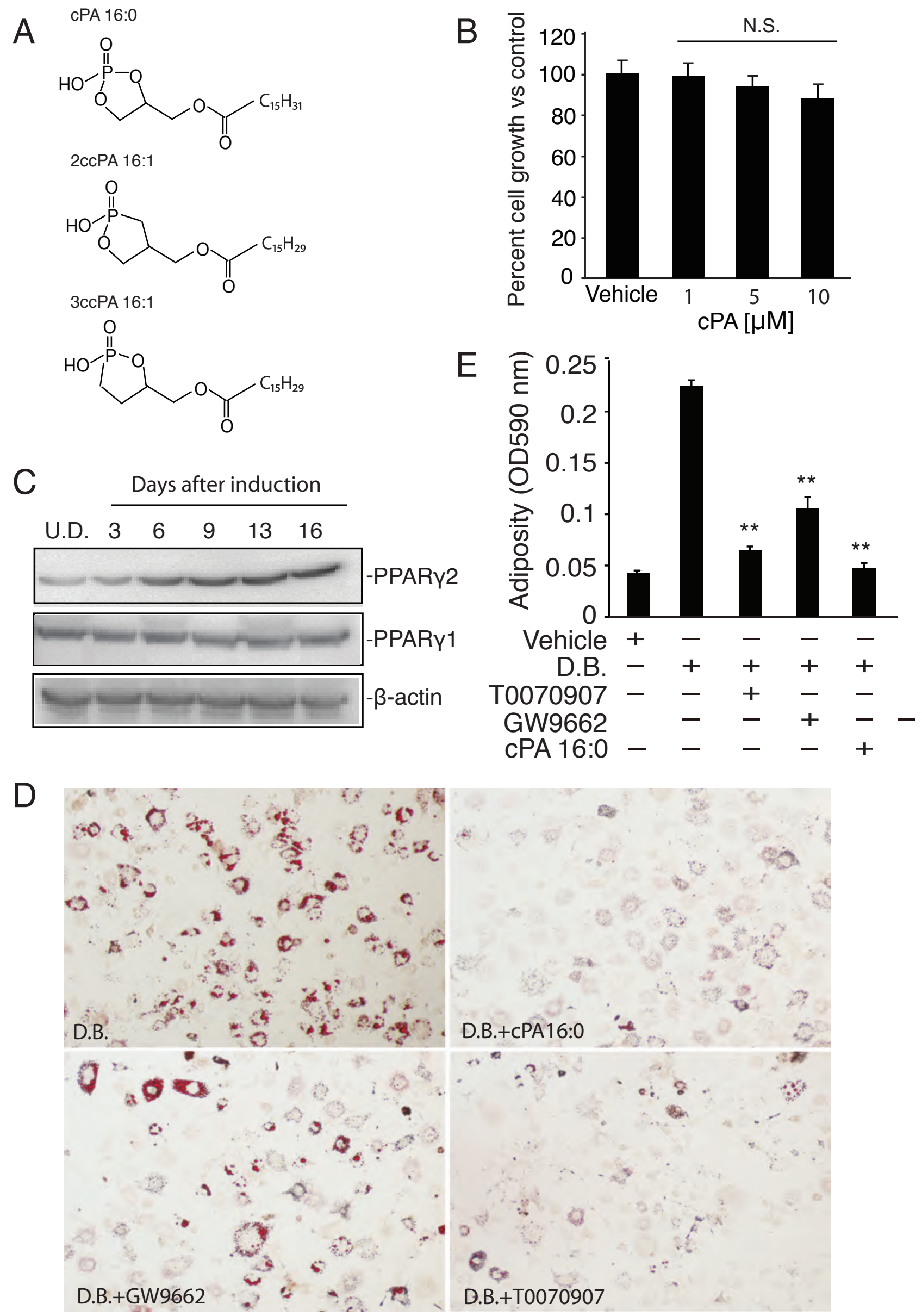

Fig.1 


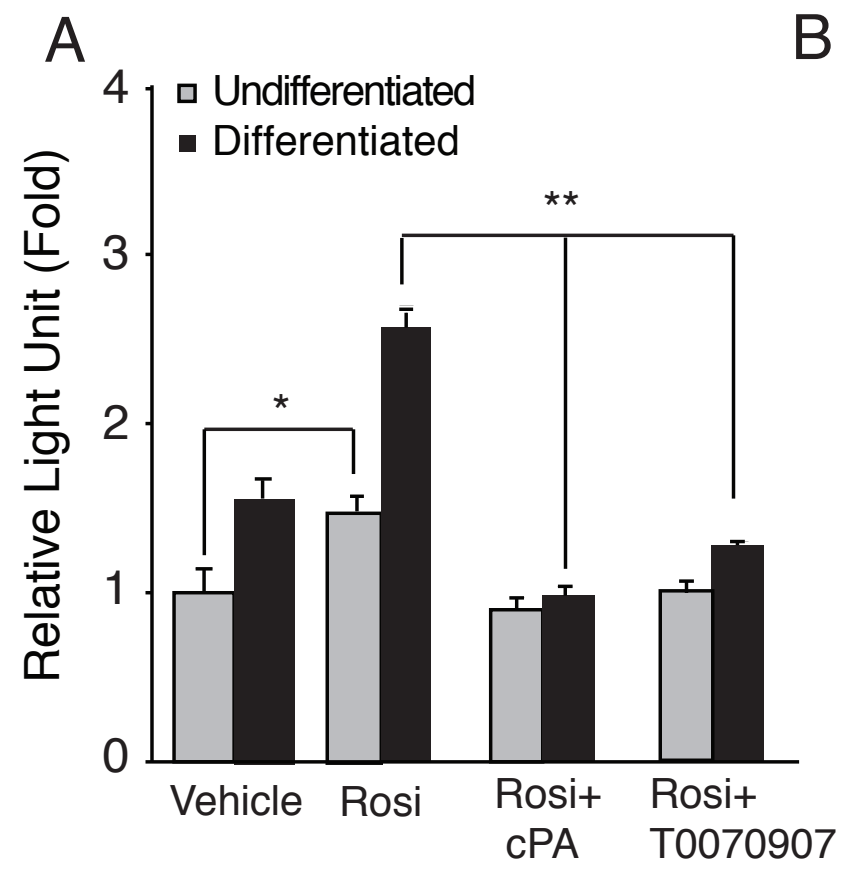

Rosi

Rosi+cPA
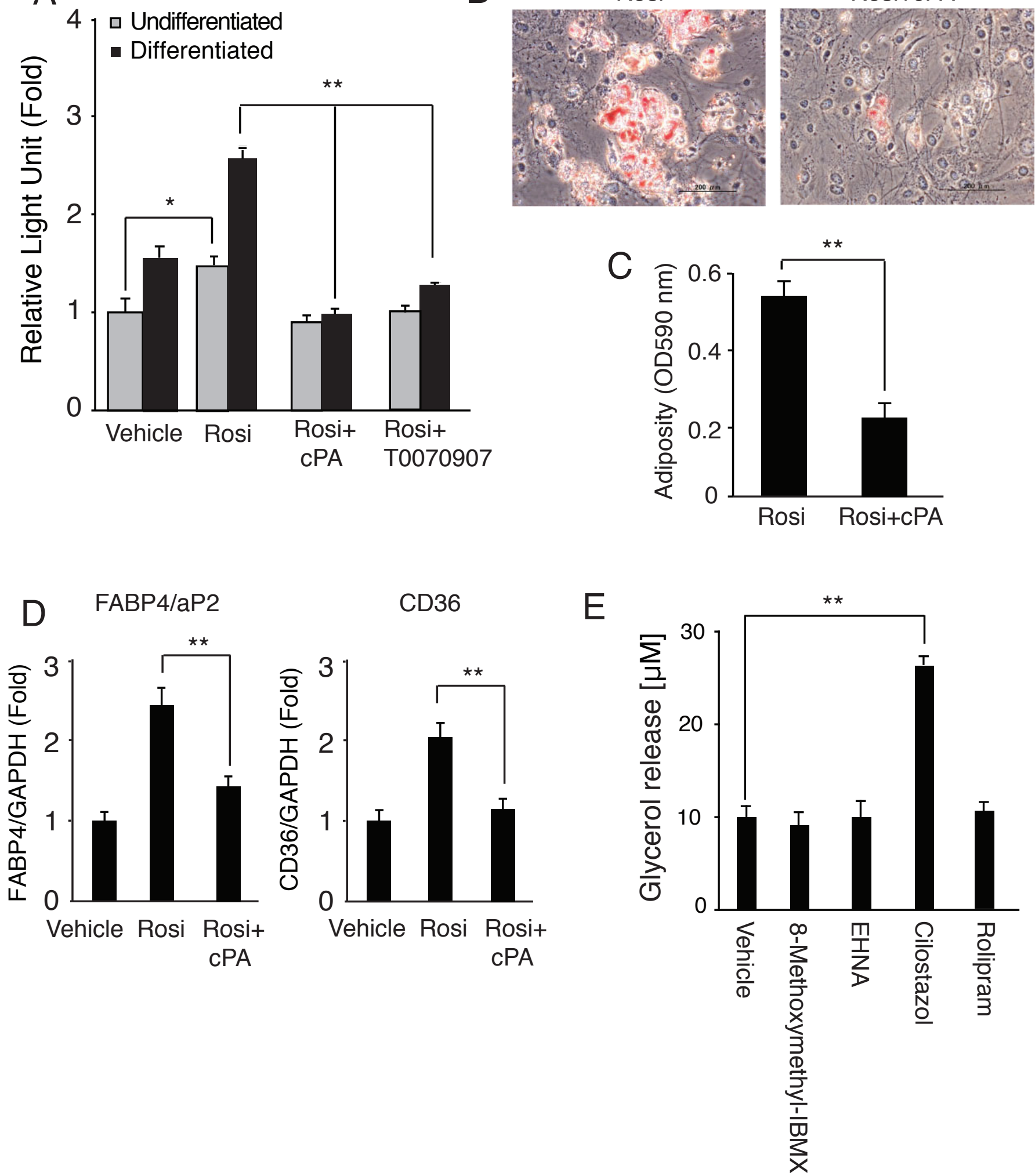

Fig.2 


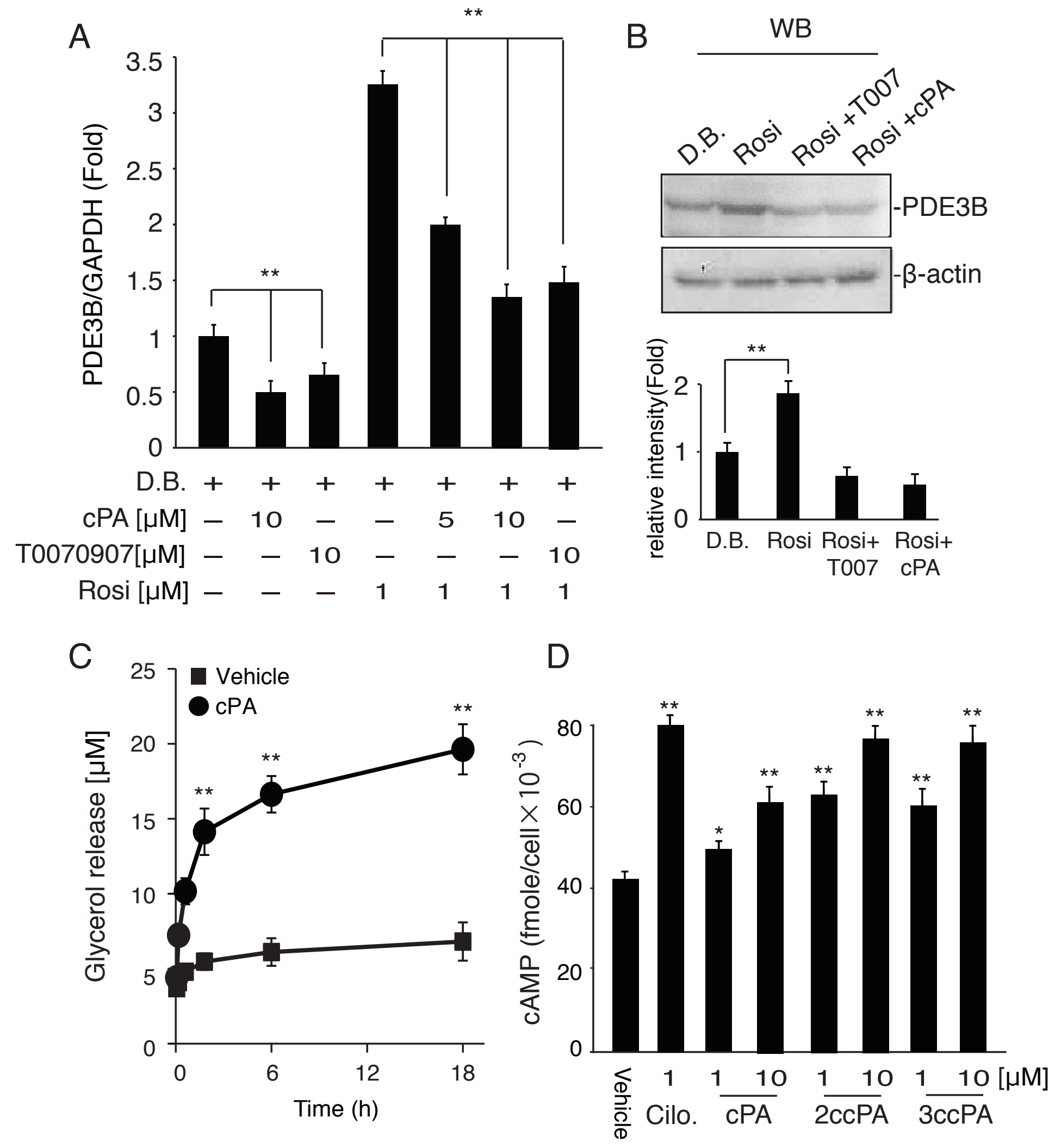

Fig.3 


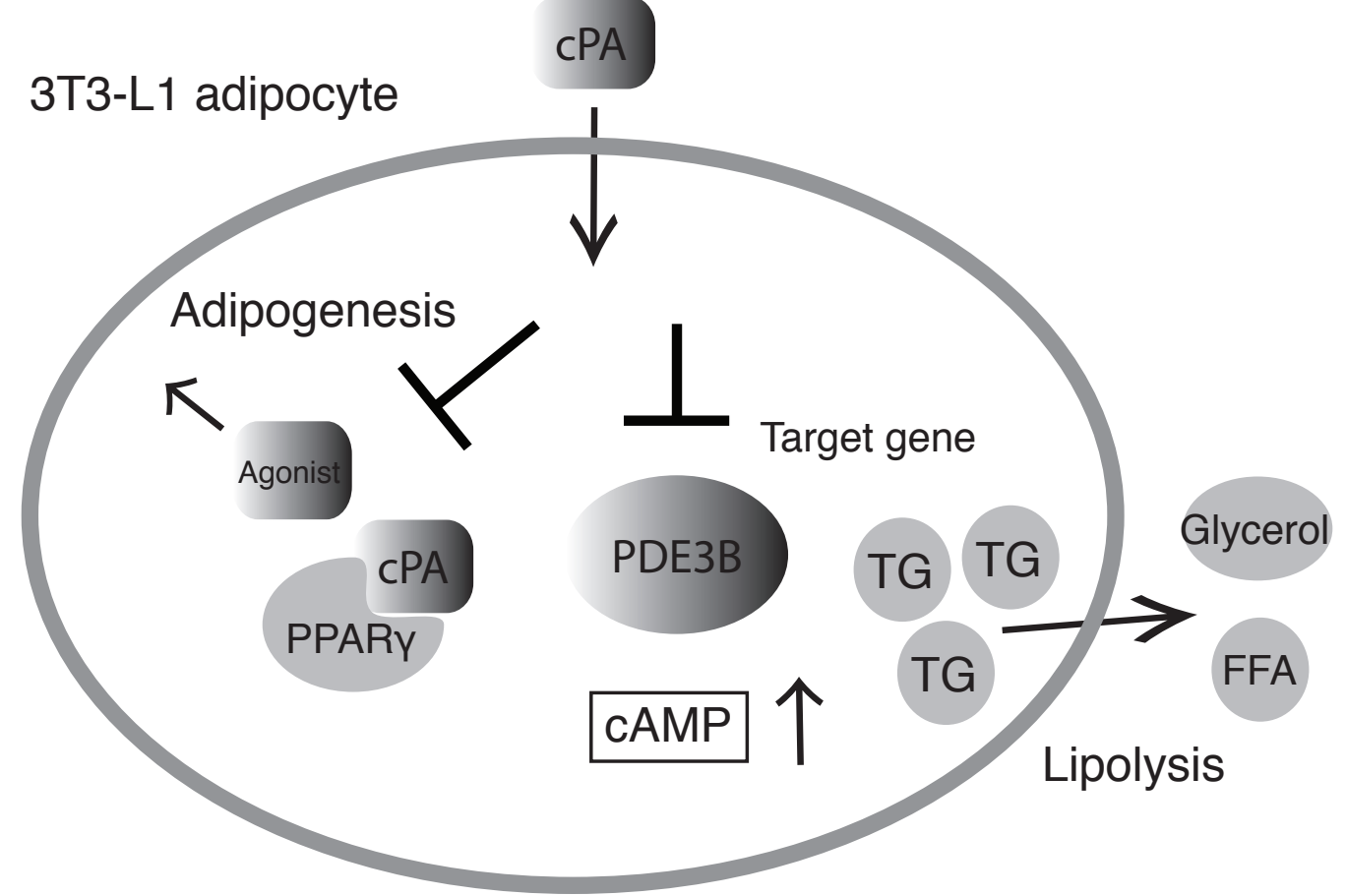

Fig.4 